Minireview

\title{
Pictorial demonstrations of photosynthesis
}

\author{
Roger P. Hangarter* \& Howard Gest \\ Department of Biology, Indiana University, Bloomington, IN 47405, USA; *Author for correspondence \\ (e-mail: rhangart@bio.indiana.edu; fax: +1-812-855-6082)
}

Received 15 April 2003; accepted in revised form 14 May 2003

Key words: action spectra, chlorophyll fluorescence, chloroplast movement, Theodor Engelmann, Hans Molisch, photoinhibition, photosynthesis, starch, David Walker, Julius von Sachs

\begin{abstract}
Theodor Engelmann's experiments in 1882 provided the first recorded visual demonstration of light wavelengths that are absorbed by photosynthetic pigments. Later, starch images in intact leaves were used to demonstrate photosynthesis in green plants. Similarly, light-induced chloroplast movements can form images in leaves as a result of changes in light transmittance through leaves and photoinhibition can form images that can be visualized by whole leaf chlorophyll fluorescence. This paper provides a brief account of how photosynthesis has been used to create an assortment of 'living images' that offer stunning demonstrations of various aspects of photosynthesis.
\end{abstract}

\section{Introduction}

The invention of photography began in the early $1800 \mathrm{~s}$ but the first biological subjects for photographic publication happened to be photosynthetic organisms, namely, 'British algae,' when in 1843, the botanist Anna Atkins started issuing her photographically illustrated 'British Algae: Cyanotype Impressions' (Atkins 1843). Prior to the development of long-lasting photographic methods, documentation of biological specimens was limited by the ability of illustrators and artists to capture fine details. One of the primary inventors of photography, William Henry Fox Talbot, who was also a botanist, was driven to develop stable photographic technologies not so much by the desire to understand the scientific principles behind the chemistry of photography but by the desire to use light to reveal properties of objects that were not previously perceived or recorded (Thomas 1997). Similarly, in their desire to reveal processes previously not perceived, photosynthesis researchers have on occasion, found clever ways to create 'living images,' somewhat analogous to photographs, that reveal fundamental properties of photosynthesis.

\section{Early action spectra}

Theodor Engelmann (1843-1909) almost certainly described the first experiments that employed lightinduced images of living systems as a means of obtaining new insights into the process of photosynthesis (Engelmann 1882, 1883). For his experiments, he had a microscope specially modified to project a microspectrum on the plane of a specimen on a microscope slide. The microspectrum was used to illuminate individual strands of the filamentous green alga, Chladophora in which each cell is nearly completely and evenly filled by a chloroplast. To measure photosynthetic oxygen production, the Chladophora filaments were dispersed on a microscope slide in a suspension containing aerotactic bacteria. By increasing the light being delivered through the microspectrum, Engelmann was able to observe the bacteria move as oxygen was produced, and after a short time they accumulated most abundantly at regions of the algal filaments that were illuminated with blue and red light. His drawings of the response of these living organisms provided a striking illustration of the first action spectrum of oxygenic photosynthesis (Figure 1). Engelmann also used bacterial motility to determine 


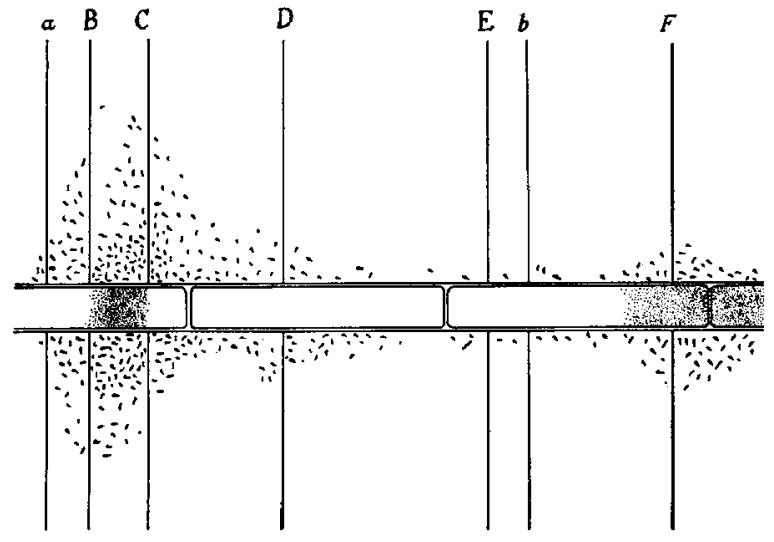

Figure 1. Engelmann's drawing of his action spectrum for oxygenic photosynthesis. A portion of a Cladophora filament is shown with swarming bacteria (B. termo) in a microspectum of light. The chloroplasts, which fill the cells uniformly, were omitted. The absorption bands of chlorophyll in the red (between B and C) and the blue/violet $(\mathrm{F})$ are indicated by stippling. Reproduced from Kamen (1986).

which components of plant cells functioned as light receptors for photosynthetic oxygen production. For this he used a modified microscope condenser that allowed him to expose small parts of photosynthetically active cells of the green alga Spirogyra, in which chloroplasts only occupy parts of each cell, to an extremely thin ray of light while in a suspension of bacteria. He observed that bacteria moved and concentrated in areas wherever parts of a chloroplast were illuminated whereas the illumination of other parts of the cell resulted in no such aggregations.

Thus, with his clever use of living organisms and light Engelmann was able to create living 'pictures' that formed the basis for the first action spectrum showing chlorophyll as the pigment driving photosynthesis and he demonstrated that chloroplasts were the cellular site of photosynthesis. Kamen (1986) has beautifully described and discussed the life and works of Engelmann.

The general validity of the action spectrum obtained by Engelmann was confirmed by Hans Molisch (1856-1937; see Molisch 1907) and, of course, was greatly refined over the years to identify the different chlorophylls and accessory pigments that constitute the complete light harvesting and energy-converting assemblies in a variety of photosynthetic organisms.

\section{Visualizing photosynthetic action by starch production}

In his pioneering work on the photosynthetic production and dark utilization of starch in green plants,

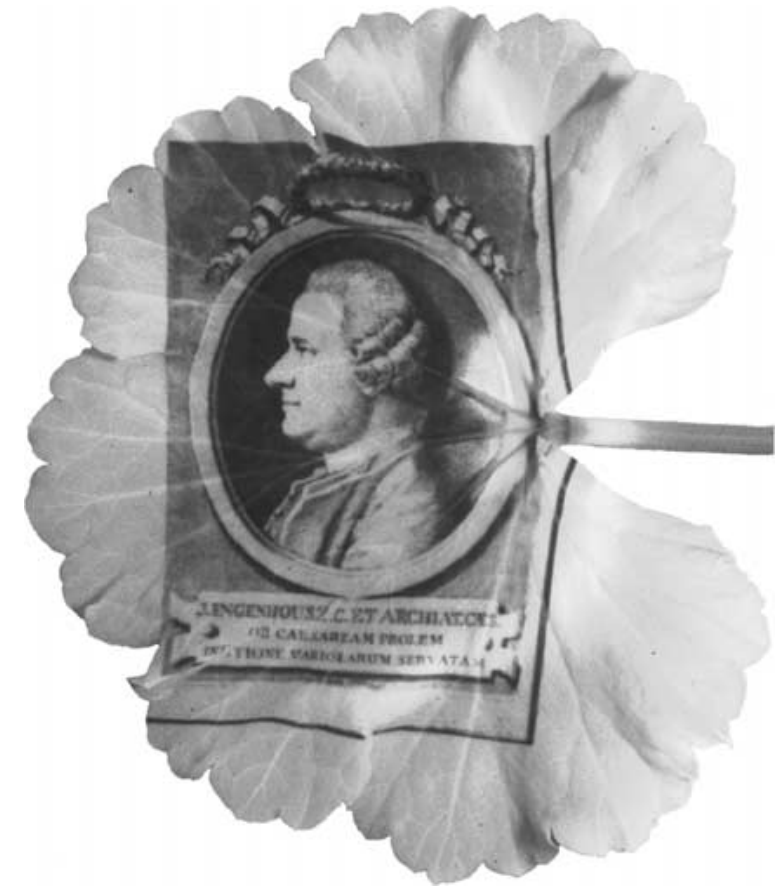

Figure 2. Starch picture of Dr Jan Ingen-Housz, one of the discoverers of photosynthesis, on a geranium leaf. The image was prepared by William Ruf and Howard Gest using a variation of Molisch's method (see Gest 1991). Light from a slide projector was passed through a photographic negative of an engraving of Ingen-Housz, and focused on a leaf (depleted of starch by prior incubation in darkness). After extracting pigments from the leaf with boiling $80 \%$ alcohol, starch granules were stained with an $\mathrm{I}_{2}-\mathrm{KI}$ solution. The Latin inscription at the bottom refers to Dr Ingen-Housz's fame as a 'smallpox inoculator.' A movie of the procedure for making starch pictures can be seen at www.cells.de/cellseng/medienarchiv/archiv/d1157.htm.

Julius von Sachs (1832-1897; see von Sachs 1864) used an iodine stain, which disclosed starch in leaves as blue or violet granules. By masking parts of leaves with foil, he was able to demonstrate that light was required for starch formation. Unlike the bacteriospectrogramm (see later) of Engelmann, which had to be recorded in drawings, the starch-stained leaves resulted in fairly stable images of photosynthetic action. Molisch (1914) expanded on von Sachs' work by developing 'starch pictures' in intact leaves by using actual photographic negatives as masks over the illuminated leaves. The level of detail in terms of both the gradations in shading that could be reproduced in his starch pictures and the spatial resolution were astonishing at the time. In such starch images, the resolution is related to the size and number of starch grains produced in each chloroplast. Thus, the starch is analogous to silver grains in a conventional photograph or 
pixels in digital images. Molisch's simple technique provides such a dramatic representation of photosynthesis in green plants that it is widely used in teaching laboratories and books to demonstrate the process (Edwards and Walker 1983; Walker 1992, see pp. 5558). Walker's favorite starch picture was a reproduction, on a geranium leaf, of a masterpiece 'Innocence' by Pierre-Paul Proudhon. An example of a starch picture using a modified version of Molisch's technique is shown in Figure 2.

\section{Imaging with chloroplast movements}

Light-induced changes in the cellular distribution or orientation of chloroplasts have been observed in species of algae, mosses, ferns, and angiosperms. Under low light conditions, chloroplasts accumulate along the cell walls that are perpendicular to the incident light. Under high light conditions, they accumulate along the walls that are parallel to the incident light. These are the regions of plant leaf cells where internal fluence rates of light are the highest and lowest, respectively, and it is believed likely that the light-induced chloroplast movements serve an adaptive function. In algae, moss and ferns, both red and blue light can cause chloroplast movements. In terrestrial angiosperms, chloroplast movements have been shown to be blue-light-specific (Inoue and Shibata 1973) but the red/far-red phytochrome photoreceptors appear to play a role in modulating the response (DeBlasio et al. 2003). In any event, chloroplast movements can have visible effects on light transmittance and reflectance properties of leaves. For example, Wada and Sugai (1994) exposed fern gametophytes masked with stenciled letters to high fluence rates of light and produced visible images of the letters in the fern gametophytes. In a more recent study in which the blue light photoreceptor phot 2 was described, Kagawa et al. (2001; see their accompanying cover picture) showed that images could also be observed in Arabidopsis leaves. The light-induced chloroplast movements are sensitive and robust enough that by using masks made from black and white photographs, it is possible to obtain detailed images that can come surprisingly close to the resolution observable with the starch images, as shown in the image of Norman Good in Figure 3. In the case of chloroplast movement images, the grain size is that of the individual chloroplasts rather than the starch granules contained within them. Moreover, chloro-

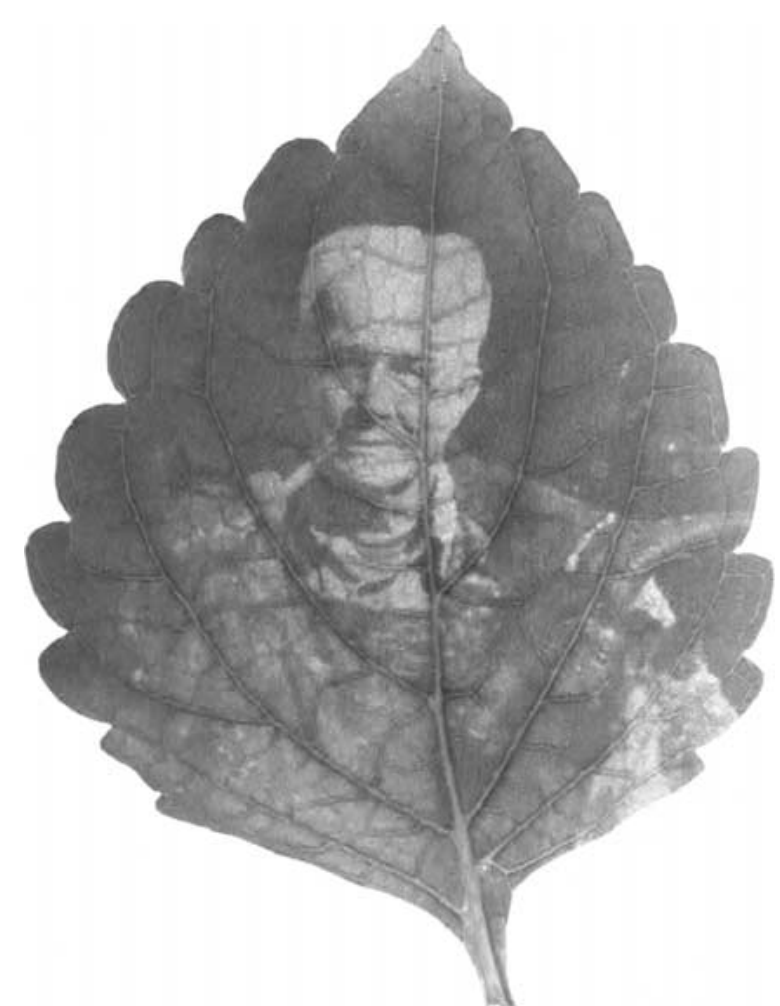

Figure 3. Image of Norman E. Good (1917-1992) in a leaf created by light-induced chloroplast movements. Norman E. Good was a photosynthesis pioneer who was instrumental in deciphering photophosphorylation and other segments of the photosynthetic electron transfer chain. He also created the 'Good buffers' (see Hangarter and Ort 1992). To create this image, a Coleus leaf was placed on a wet paper towel, covered with a laser-printed transparency and illuminated with a slide projector for $30 \mathrm{~min}$. The leaf was then photographed using blue backlighting. The image in the living leaf resulted from light-dependent changes in the cellular position of chloroplasts. The lighter areas are those that received the most light so that the chloroplasts moved to the edges of the cells allowing more light to be transmitted through the leaf in those areas. 'Gray-scale' resolution is possible since in areas receiving non-saturating intensities, there is a gradient of chloroplast movement in different cell layers. See http://sunflower.bio.indiana.edu/ rhangart/plantmotion for more details about creating images with chloroplast movements.

plast movement-induced images can be observed in living leaves without the need for chemical stains and the same leaf can be used over and over to create new images simply by changing the masking image and re-exposing the leaf to light.

\section{Chlorophyll fluorescence images}

With the availability of digital cameras capable of capturing images from chlorophyll fluorescence, it is possible to measure photoinhibition and non- 


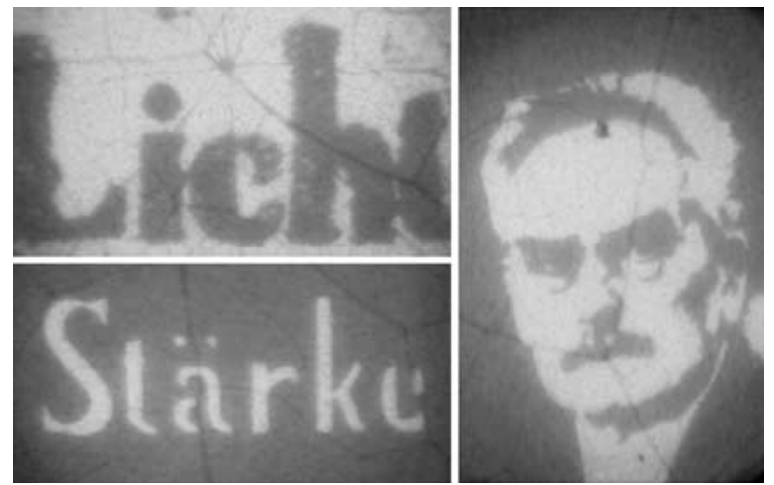

Figure 4. Chlorophyll fluorescence printing using artifacts of the starch printing technique developed by H. Molisch. These images (provided by Barry Osmond) were made by exposing Cissus leaves to excess light under a negative of a 70-year-old dried leaf starch printed with 'Licht' by Molisch (upper left), a stencil of 'Stärke' used by Molisch (lower left), and a negative of Molisch (right). The fluorescent images were captured after $10 \mathrm{~min}$ of dark acclimation and showed no external evidence of the treatments (see Osmond et al. 1999).

photochemical quenching over the surface of an entire living leaf. By exposing living leaves that were masked with photographic negatives to photodamaging light intensities, Ning et al. $(1995,1997)$ and Osmond et al. (1999) created a number of stunning chlorophyll $a$ fluorescence images in living leaves (see an example in Figure 4). Analysis of variable chlorophyll $a$ fluorescence data from different regions of such imaged leaves together with high resolution analysis of this fluorescence by confocal microscopy demonstrated that the fluorescence images created in live leaves were due to photoinhibition of Photosystem (PS) II in grana stacks (Osmond et al. 1999). Amazingly, in excised Cissus leaves, fluorescence images produced by photodamage during the initial exposure could be observed for as long as 10 days, although with much reduced contrast since some repair probably occurred (Osmond et al. 1999).

\section{Pictures from light-motile organisms}

Photobiologists have also used live imaging techniques in studies of light-dependent behavior in various organisms. Engelmann (1883) again led the way when he used his microspectrum to irradiate motile photosynthetic bacteria of the genus Chromatium in a film on a microscope slide. The cells accumulated in bands that corresponded closely to the in vivo absorbance bands of bacteriochlorophyll and carotenoids
(Gest 1995). In this experiment, formation of the 'bacteriospectrogramm' resulted from scotophobic ('fear of darkness') sensory behavior rather than phototaxis (i.e., movement directed toward or away from a light source) (Gest 1995). Thus, numerous cells become 'trapped' in zones that correspond to the absorption peaks of the active photopigments. Häder (1984) created an amazingly detailed 'algograph' by projecting a photographic negative of the Freiburg Münster onto a homogeneous suspension of Phormidium spp. The bacteria accumulated in different areas, depending on fluence rates, and the image was vividly reproduced in the culture dish. Using some highly motile strains of purple bacteria, Hustede et al. (1989) demonstrated that by projecting a black and white transparency onto a cuvette containing a bacterial suspension, the bacteria could dramatically reproduce the picture in the cuvette after just $5 \mathrm{~min}$ of exposure.

\section{Teaching with photosynthetic art}

Engelmann's initial experiments to determine an action spectrum for photosynthesis, and the various other photosynthetically-produced images that followed have all played roles in demonstrating fundamental aspects of photosynthesis. It is interesting that so many scientists were inspired enough by their scientific observations to extend their studies to create what amounts to 'living art.' Interestingly, British artists Heather Ackroyd and Dan Harvey have been creating art installations since 1990 in which they project pictures onto large panels of grass, which results in reproduction of the images in green and yellow tones depending on the amount of chlorophyll produced in the grass (Barnes 2001; see also www.artsadmin.co.uk/artists/ah). Although their work has been motivated from the vantage of the arts, the science of chlorophyll production and degradation is the foundation on which their striking works are created. Clearly some commonality exists in the creative processes exhibited in the sciences and arts [see also the paintings by Antoinette Ryter reproduced in Govindjee et al. (2003)]. Moreover, the visually striking results of these various techniques are excellent teaching tools that offer dramatic demonstrations of current interpretations of important processes like photoinhibition, photoprotection, and photoadaptation. Many of the techniques can be easily adapted for teaching in classes at nearly all levels and some are simple enough for use in more public forums, such 
as science museums where they could be instrumental in educating the general public about the critical role plants serve in global biology. A picture may be worth a thousand words but a carefully created living image may speak volumes.

\section{Acknowledgments}

The first author (RPH) would like to express his gratitude to Norman Good, who took him into his lab and proceeded to provide the education of a lifetime. RPH would also like to acknowledge his co-author Howard Gest and all of the Emeritus Professors at Indiana University and elsewhere who continue to enrich our lives with their wisdom. We thank Barry Osmond for providing the images shown in Figure 4. RPH thanks the National Science Foundation (IBN-0080783) and the Department of Energy (DE-FG02-01ER15223) for research support. We thank David Walker for his suggestions. This paper was edited by Govindjee.

\section{References}

Atkins A (1843) British Algae: Cyanotype Impressions, pp 1843-1853, 3 volumes, privately published, Halstead Place, Sevenoaks, UK

DeBlasio SL, Mullen JL, Luesse DL and Hangarter RP (2003) Phytochrome modulation of blue-light-induced chloroplast movements in Arabidopsis. Plant Physiol 133: 1471-1479

Barnes M (2001) Photos on the grass (at last): the chlorophyll apparitions of Ackroyd and Harvey. Aperture 165: 66-71

Edwards GE and Walker DA (1983) C3, C4, Mechanisms, and Cellular and Environmental Regulation of Photosynthesis, pp 205-208. Blackwell Scientific Publications, Oxford

Engelmann TW (1882) Uber Sauerstoffausscheidung von Pflanzenzellen im Mikrospectrum. Bot Z 40: 419-426

Engelmann TW (1883) Bacterium photometricum. Ein Betrag zur vergleichenden Physiologie des Licht- und farbensinnes. Arch Physiol 30: 95-124

Gest H (1991) The legacy of Hans Molisch (1856-1937), photosynthesis savant. Photosynth Res 30: 49-59

Gest H (1995) Phototaxis and other sensory phenomena in purple photosynthetic bacteria. FEMS Microbiol Rev 16: 287-294
Gest H (1997) A 'misplaced chapter' in the history of photosynthesis research; the second publication (1796) on plant processes by Dr Jan Ingen-Housz, MD, discoverer of photosynthesis. Photosynth Res 53: 65-72

Govindjee, Beatty JT and Gest H (2003) Celebrating the millenium - historical highlights of photosynthesis research, Part 2. Photosynth Res 76: 1-11

Häder DP (1984) Wie orienteren sich Cyanobakterien im licht? Biol Unserer Zeit 14: 78-83

Hangarter RP and Ort DR (1992) Norman E. Good (1917-1992). Obituary. Photosynth Res 34: 245-247

Hustede E, Liebergesell M and Schlegel HG (1989) The photophobic response of various sulphur and nonsulphur purple bacteria. Photochem Photobiol 50: 809-815

Inoue Y and Shibata K (1973) Light-induced chloroplast rearrangements and their action spectra as measured by absorption spectroscopy. Planta 114: 341-358

Kagawa T, Sakai T, Suetsugu N, Oikawa K, Ishiguro S, Kato T, Tabata S, Okada K and Wada M (2001) Arabidopsis NPL1: a phototropin homolog controlling the chloroplast high-light avoidance response. Science 291: 2138-2141

Kamen MD (1986) On creativity of eye and ear: a commentary on the career of T.W. Engelmann. Proc Am Phil Soc 130: 232-246

Molisch H (1914) Ueber die Herstellung von Photographien in einem Laubblatte. Sitzungsber Kaiserl Akad Wissen MathNaturwiss KI CXXIII: 923-931

Ning L, Edwards GE, Strobel A, Daley LS and Callis JB (1995) Imaging fluorometer to detect pathological and physiological change in plants. Appl Spectrosc 49: 1381-1389

Ning L, Peterson BE, Edwards GE, Daley LS and Callis JB (1997) Recovery of digital information stored in living plant leaf photosynthetic apparatus as fluorescence signals. Appl Spectrosc 51: $1-9$

Osmond B, Schwartz O and Gunning B (1999) Photoinhibitory printing on leaves, visualized by chlorophyll fluorescence imaging and confocal microscopy, is due to diminished fluorescence from grana. Aust J Plant Physiol 26: 717-724

Thomas A (1997) Beauty of Another Order: Photography in Science, p 256. Yale University Press and National Gallery of Canada, New Haven, Connecticut

von Sachs J (1864) Ueber die Auflösung und Wiederbildung des Amylums in den Chlorophyllkörnern bei wechselnder Beleuchtung. Bot Z 22(38): 289-294

von Sachs J (1887) Lectures on the Physiology Plants. Translated by HM Ward, pp 309-322. Clarendon Press, Oxford

Wada M and Sugai M (1994) Photobiology of ferns. In: Kendrick RE and Kronenberg GHM (eds) Photomorphogenesis in Plants, pp 783-802. Kluwer Academic Publishers, Dordrecht, The Netherlands

Walker DA (1992) Energy, Plants \& Man (2nd edition), pp 57-58. Oxygraphics, Brighton, UK 